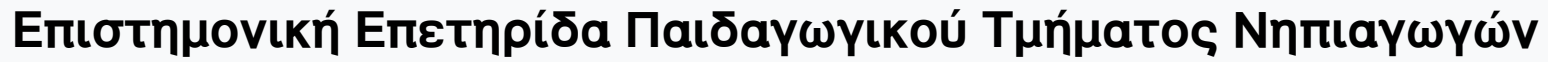 חaveriotnuíou lwavvívwv
}

Tóp. 1 (1997)

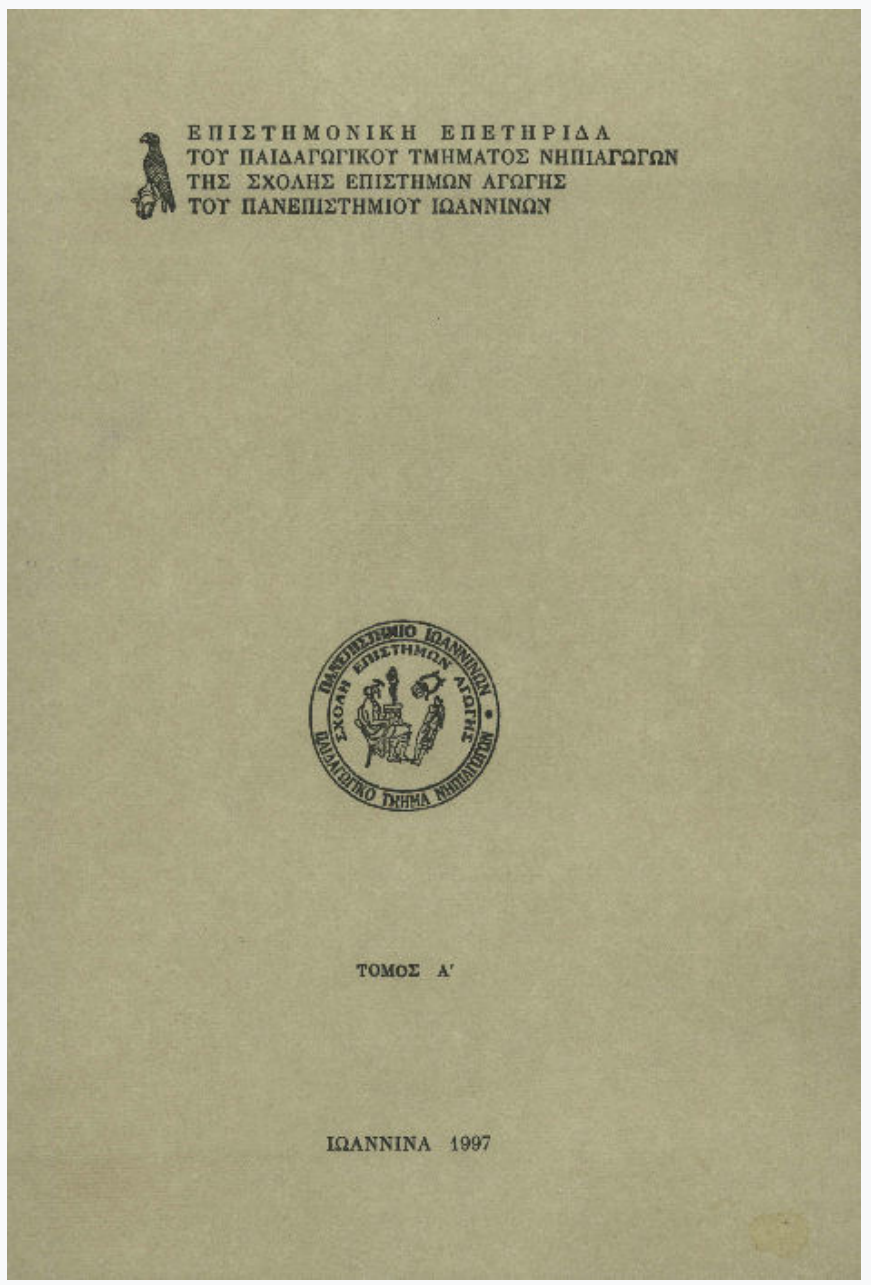

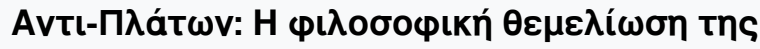

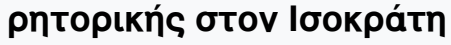

Хара́ланпос Апобтоло́почиос

doi: $\underline{10.12681 / \text { jret.937 }}$

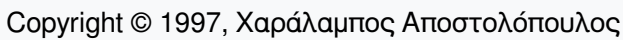

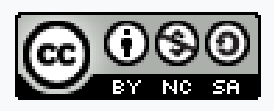

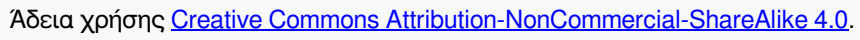

\section{Bıß入ıорачıкń avaчорá:}

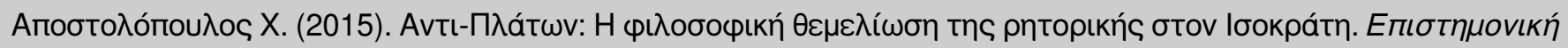

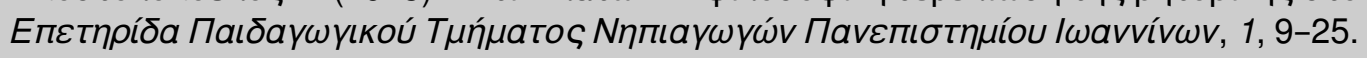

https://doi.org/10.12681/jret.937 


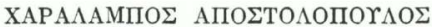

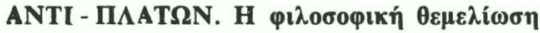

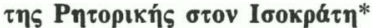

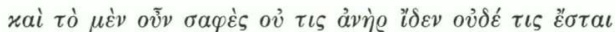

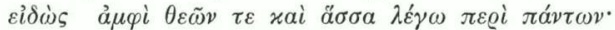

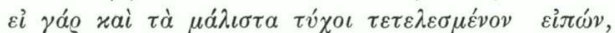

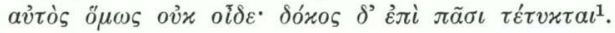

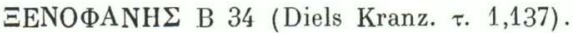

\section{$\operatorname{MEPO\Sigma } \mathrm{A}^{\prime}$}

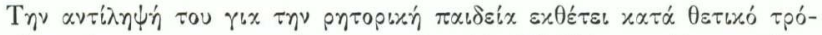

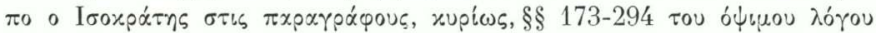

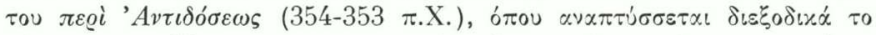

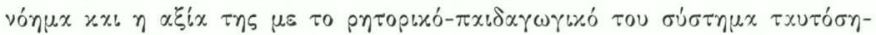

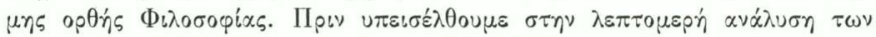

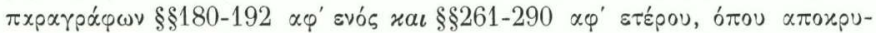

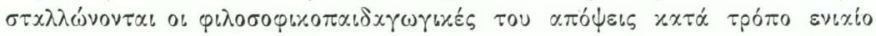

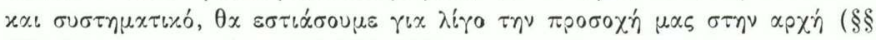

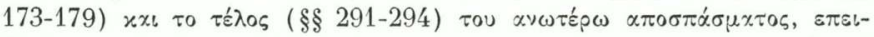

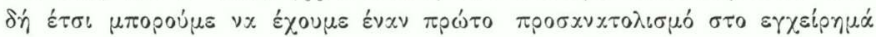

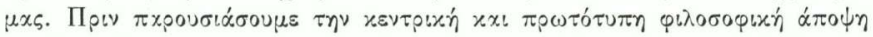

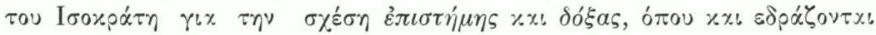

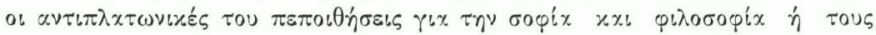

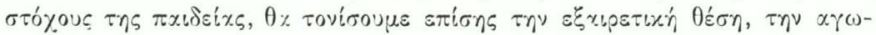

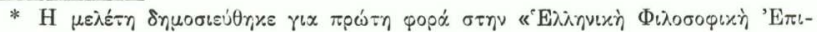

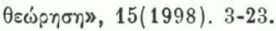

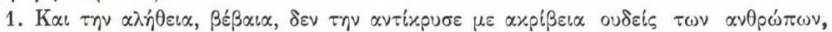

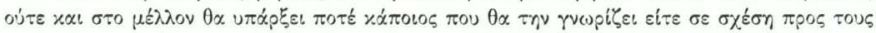

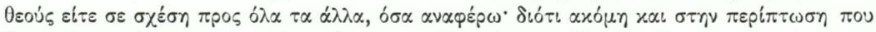

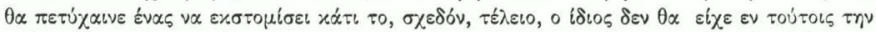

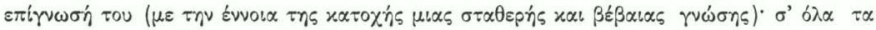

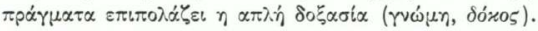




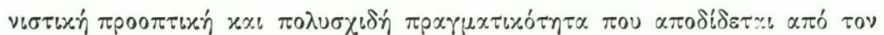

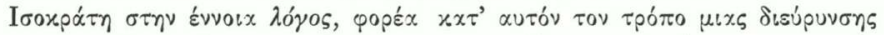

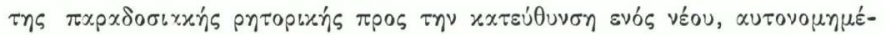

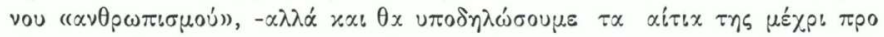

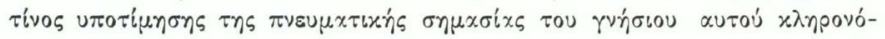

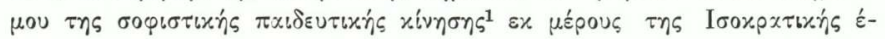

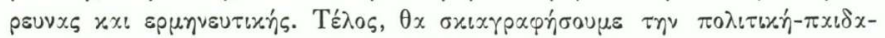

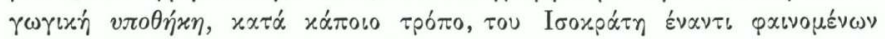

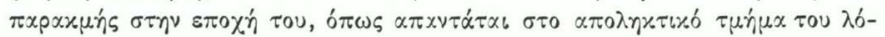

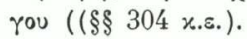

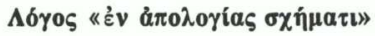

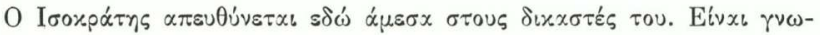

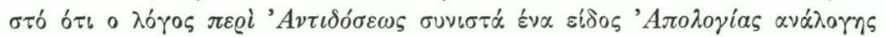

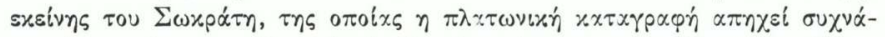

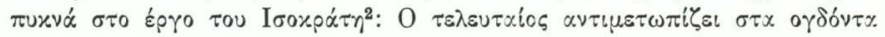

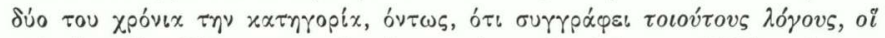

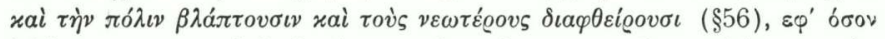

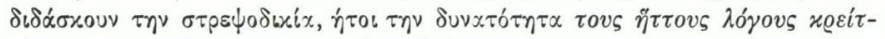

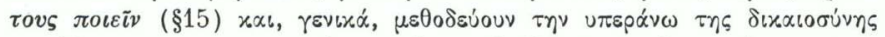

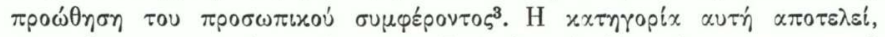

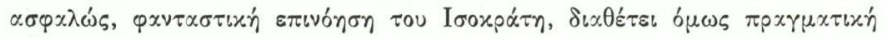

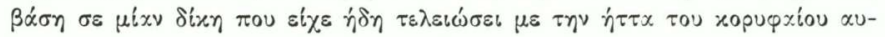

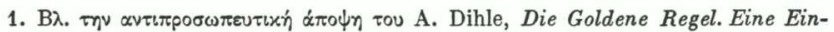
führung in die Geschichte der antiken und frühgriechischen Vulgärethik, Göttin-

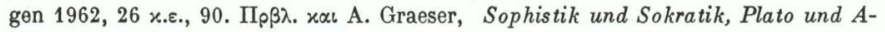

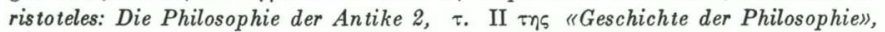
hrsg. v.W. Röd, München 1983, 80 x.ع.

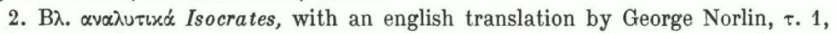
London 1991 (11928), xvii (General introduction) $x_{\alpha} \tau .2$, London 1992 (11929),

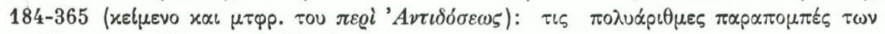

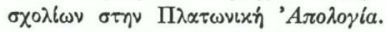

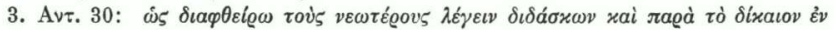

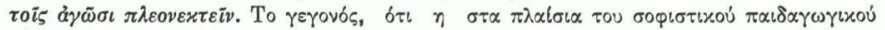

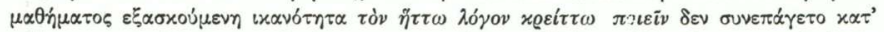

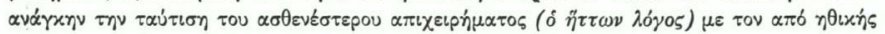

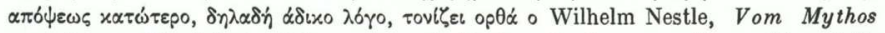
zum Logos. Die Selbstentfaltung des griechischen Denkens von Homer bis auf die Sophistik und Sokrates, Stuttgart ${ }^{2} 1975$ (11940), 258. 


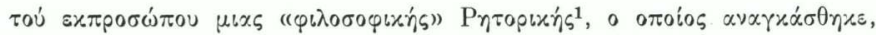

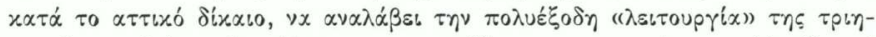

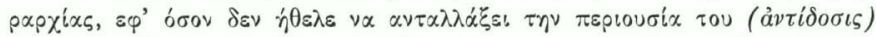

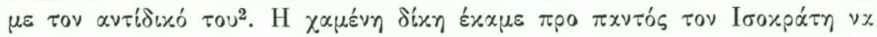

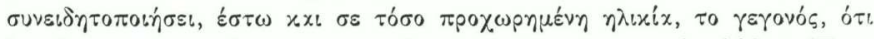

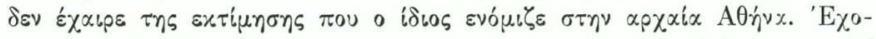

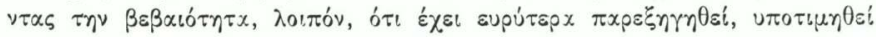

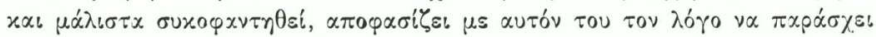

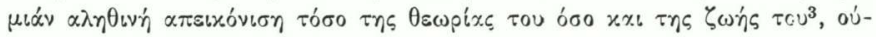

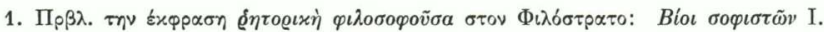

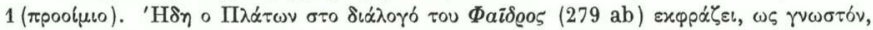

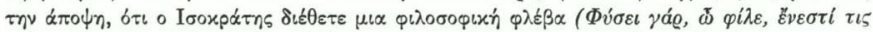

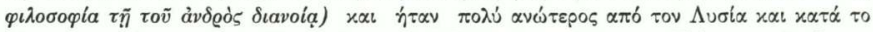

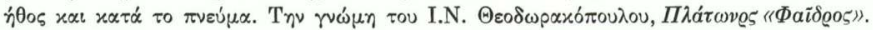

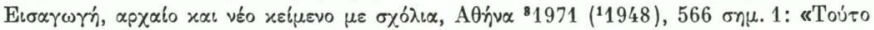

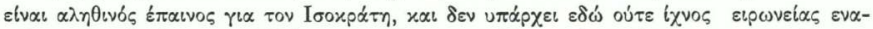

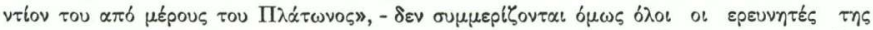

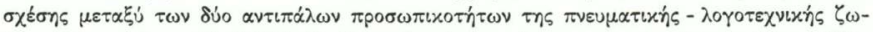

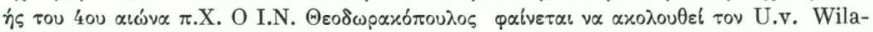
mowitz, Platon II, Beilagen und Textkritik, Berlin ${ }^{3} 1962$ (1920), 122. ("keine Spur von Ironie»), '́ $\pi \omega \varsigma \alpha \lambda \lambda \omega \sigma \tau \varepsilon$ к $\alpha$ ot R. Hackforth, Plato's Phaedrus. Translated with Introduction and Commentary, Cambridge 1952, 167, W. Jaeger, Paideia III,

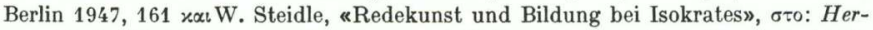

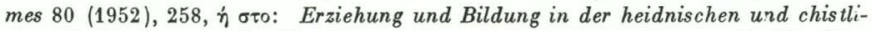

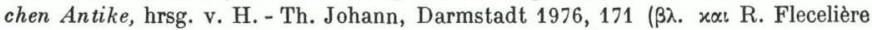

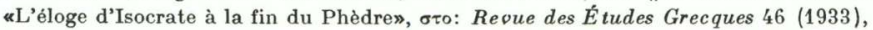

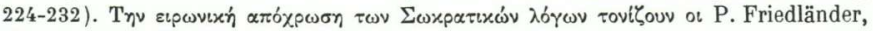
Platon III, Berlin '1960, 221 xal, xupi ${ }^{3}$, G. J. De Vries, A Commentary on the Phaedrus of Plato, Amsterdam 1969, 264 ("A mordant sarcasm), $\mu \varepsilon \pi \propto p \alpha \pi \circ \mu \pi \dot{n}$

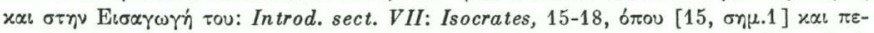

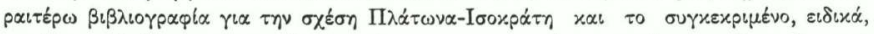

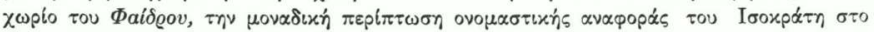

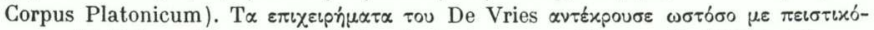

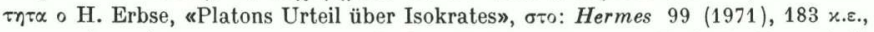

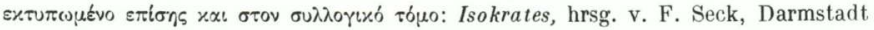

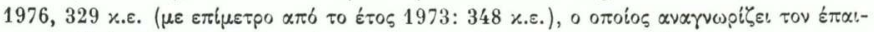

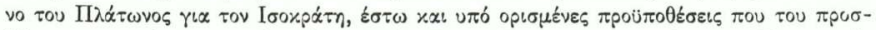

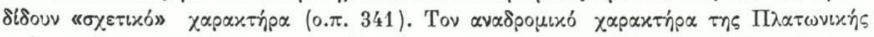

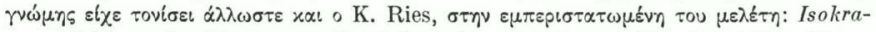

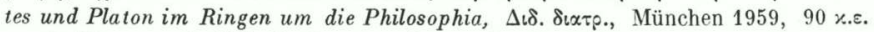

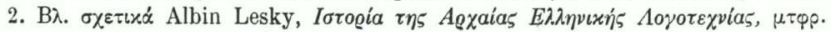

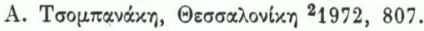

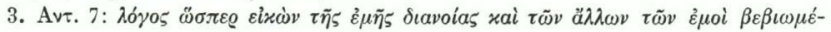
$\nu \omega \nu$. 


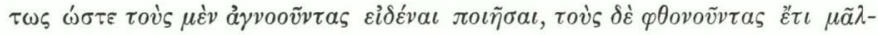

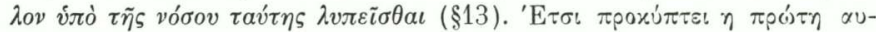

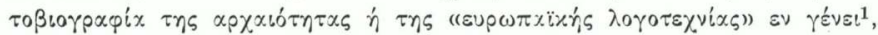

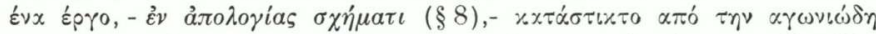

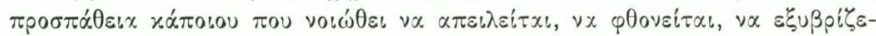

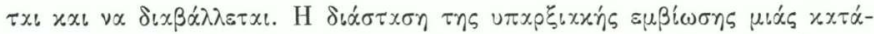

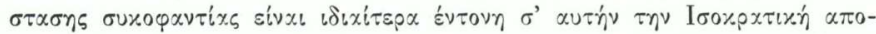

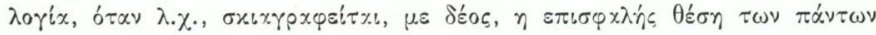

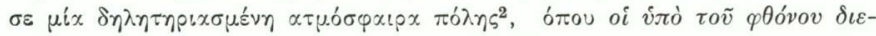

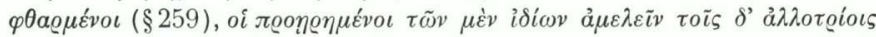

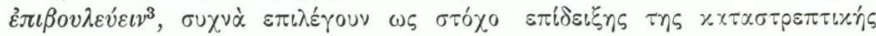

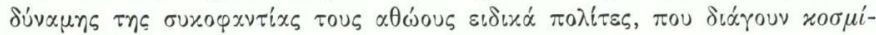

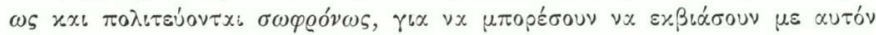

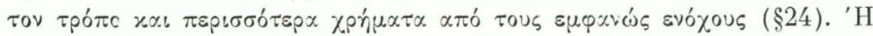

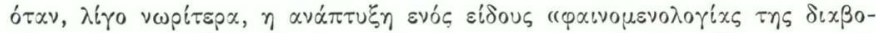
$\lambda \hat{n} \varsigma)$, -

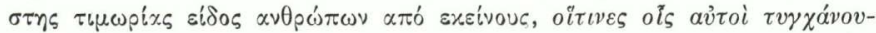

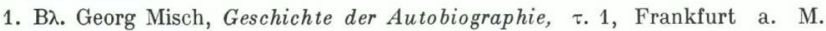

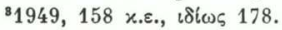

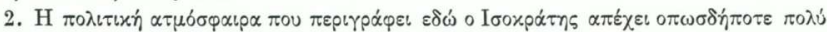

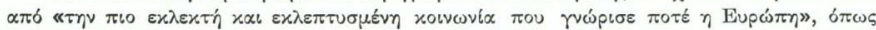

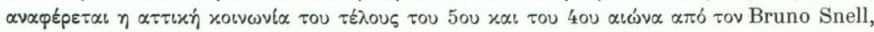

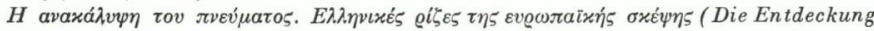
des Geistes. Studien zur Entstehung des europäischen Denkens bei den Griechen, Göttingen 41975), $\mu \tau \varphi \rho . \Delta$. I. I $\alpha x \omega \dot{\beta}, \mathrm{A} \theta \dot{\eta} v \alpha{ }^{3} 1989,340$.

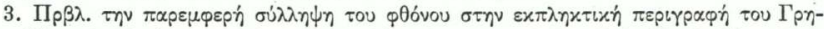

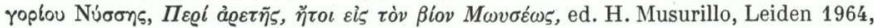

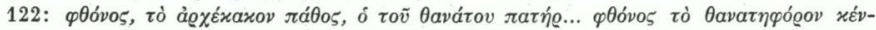

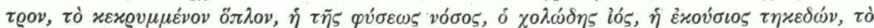

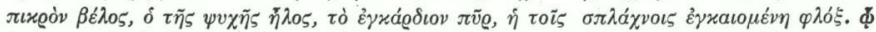

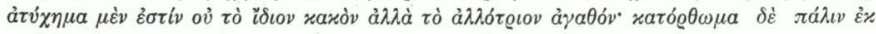

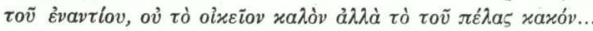

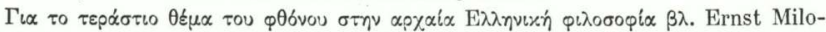
benski, Der Neid in der Griechischen Philosophie, Wiesbaden 1964 (Klassisch-Phi-

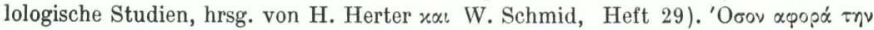

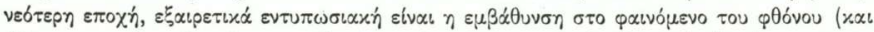

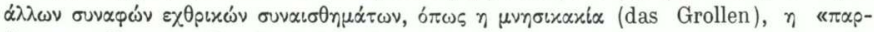

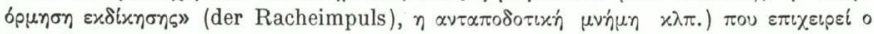

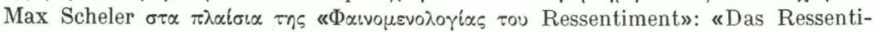

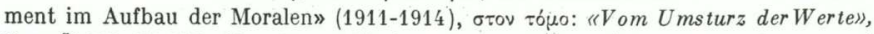

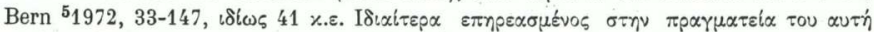

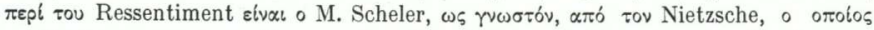

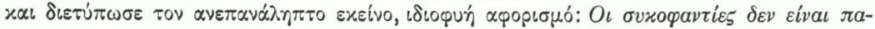




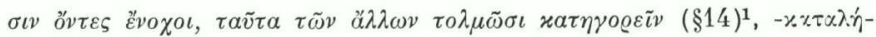

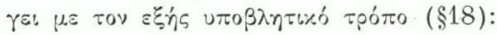

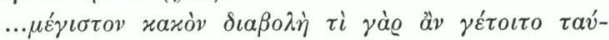

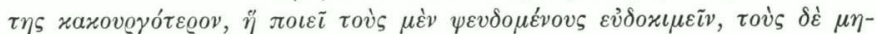

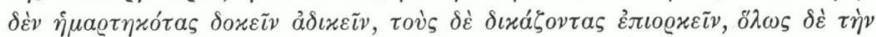

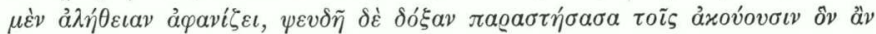

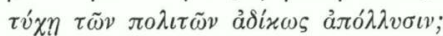

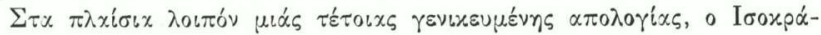

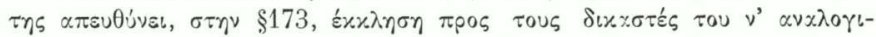

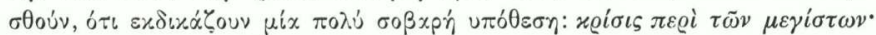

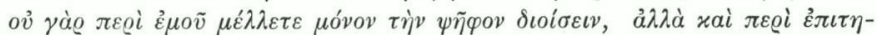

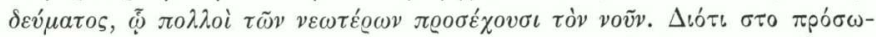

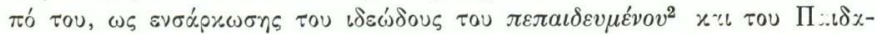

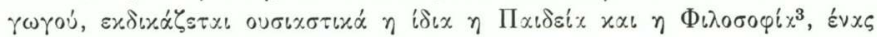

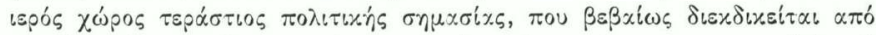

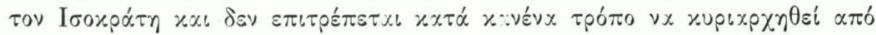

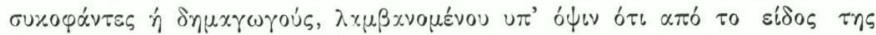

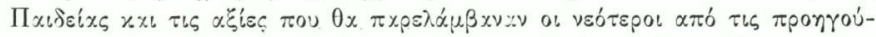

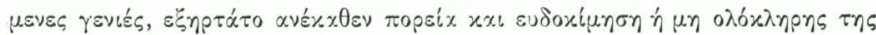

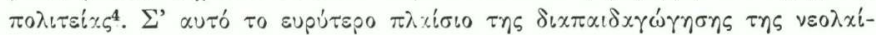

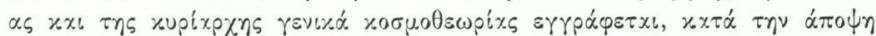

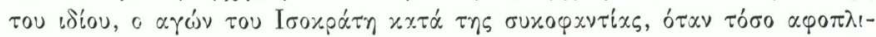

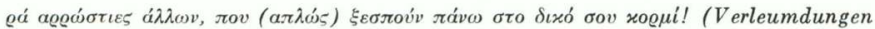

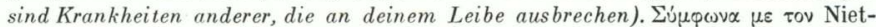

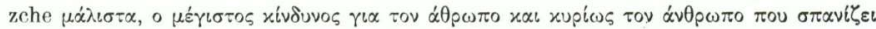

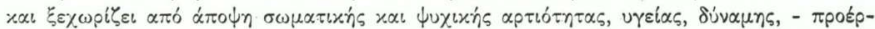

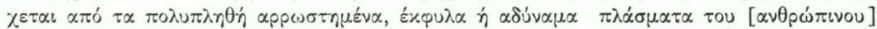

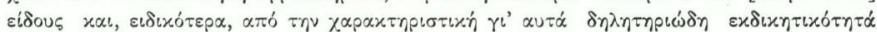

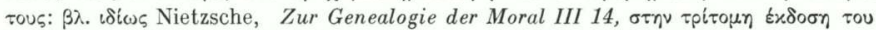

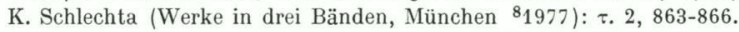

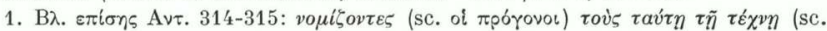

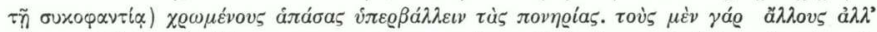

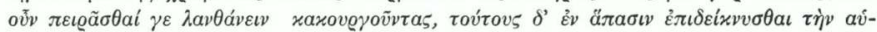

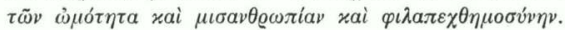

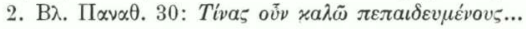

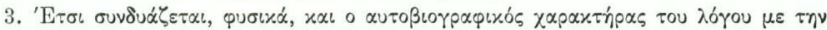

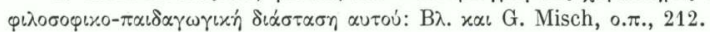

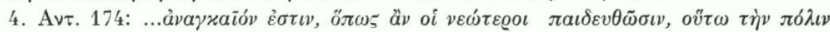

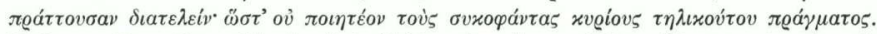

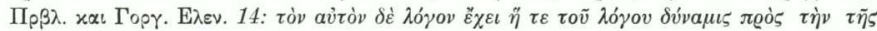

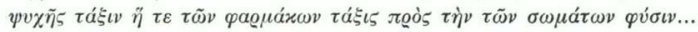




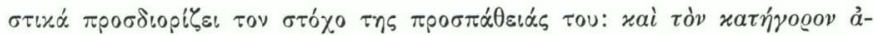

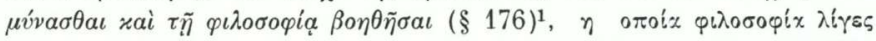

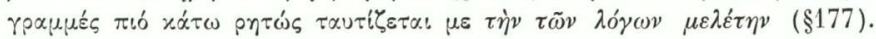

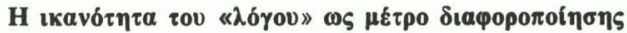

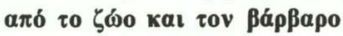

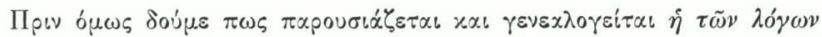
$\mu \varepsilon \lambda \varepsilon \dot{\varepsilon} \tau \eta \eta \eta$

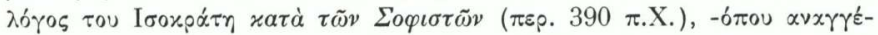

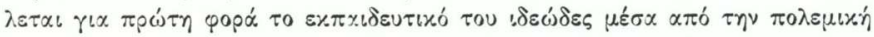

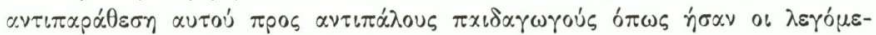

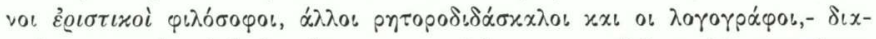

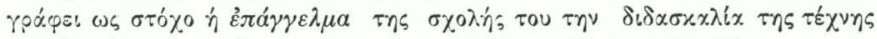

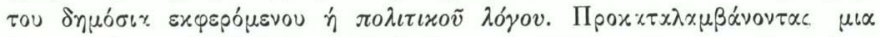

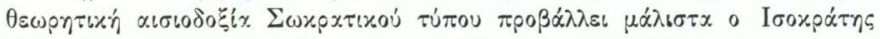

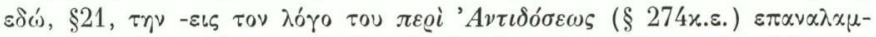

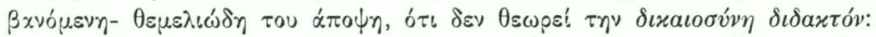

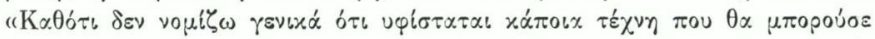

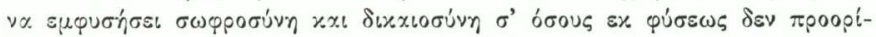

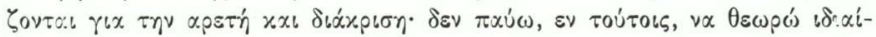

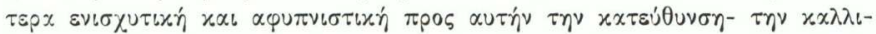

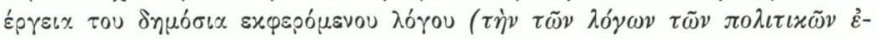

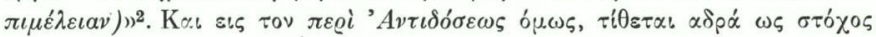

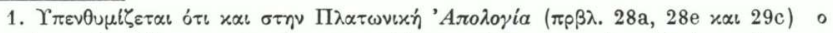

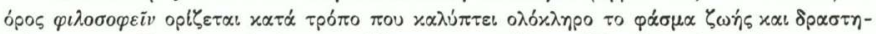

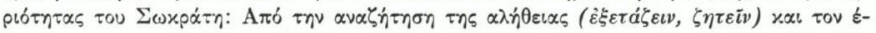

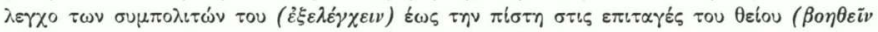

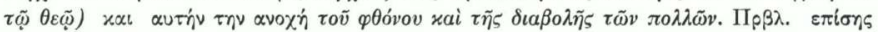

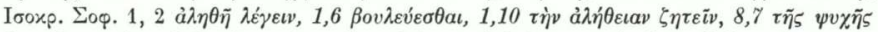

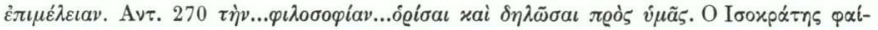

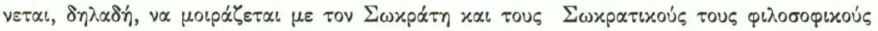

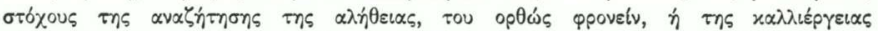

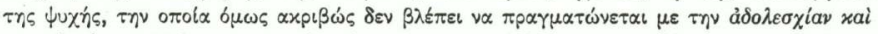

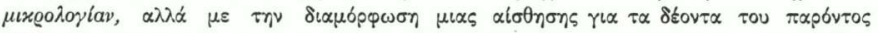

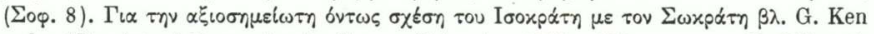

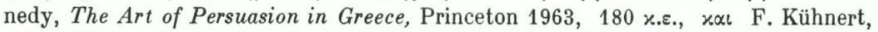
«Die Bildungskonzeption des Isokrates», бто: Der Mensch als Maß der Dinge, hrsg. v. R. Müller, Berlin 1976, 328 x.ع.

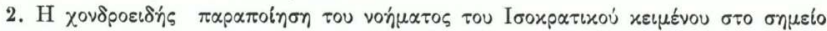

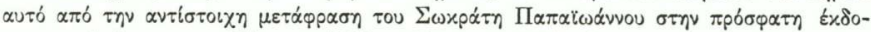

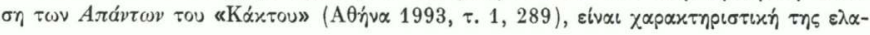




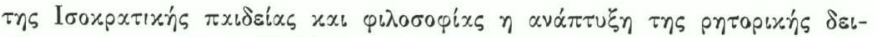

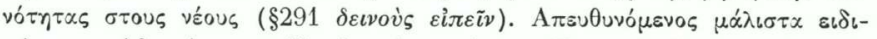

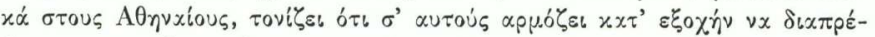

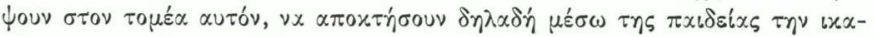

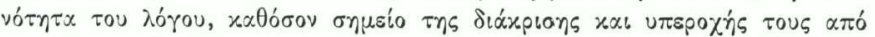

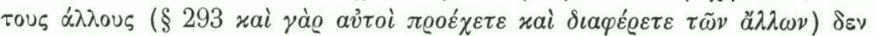

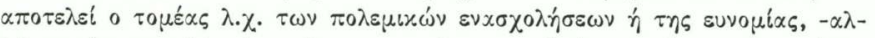

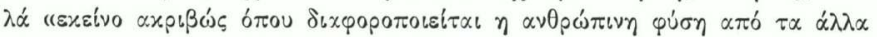

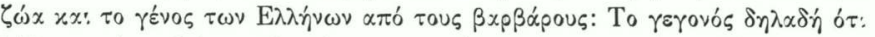

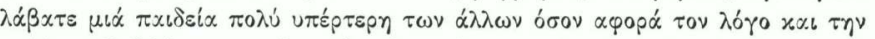

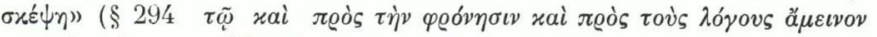
$\pi \varepsilon \pi \alpha \iota \delta \varepsilon \tilde{v} \sigma \theta \alpha \iota \tau \tilde{\omega} \nu \stackrel{\alpha}{\lambda \lambda \omega \nu})^{1}$.

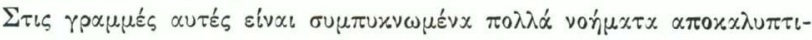

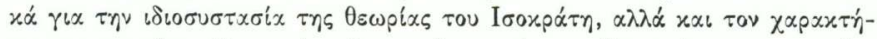

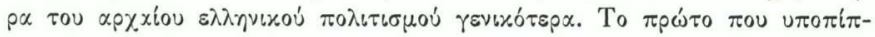

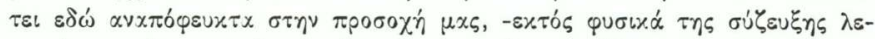

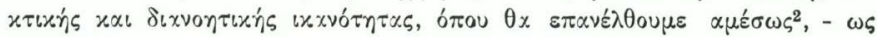

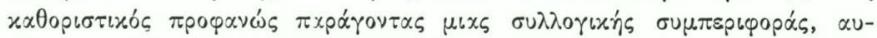

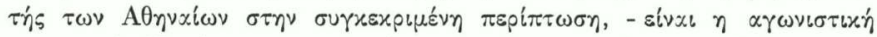

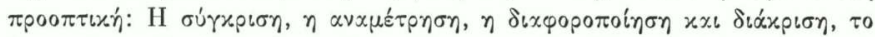

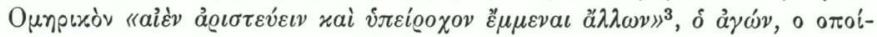

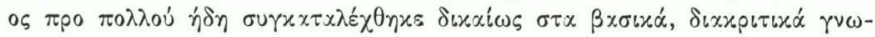

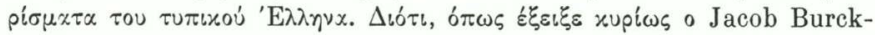

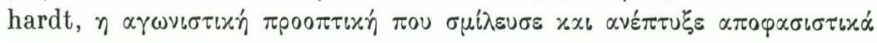

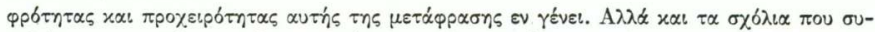

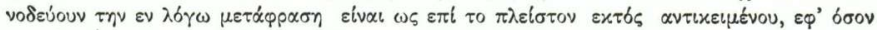

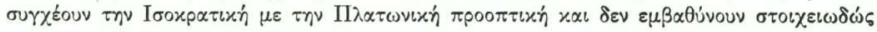

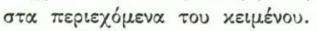

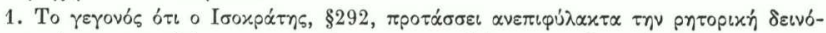

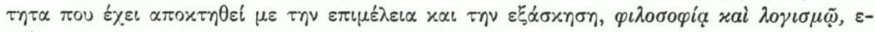

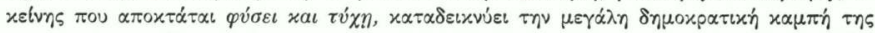

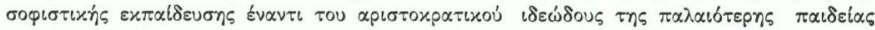

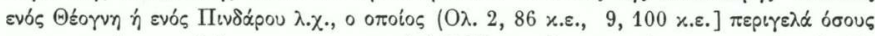

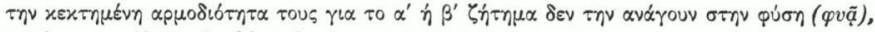

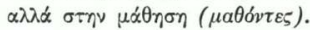

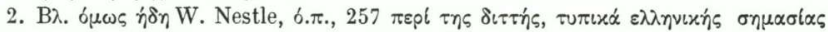

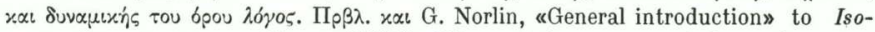

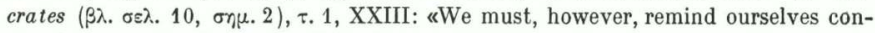
stantly in reading Isocrates that discourse, $\lambda 6 \gamma \circ 5$, is both the outward and the inward thought: it is not merely the form of expression, but reason, feeling, and imagination as well».

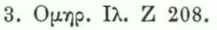




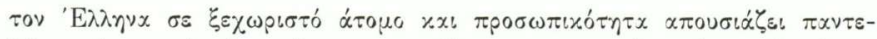

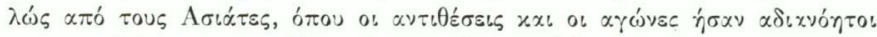

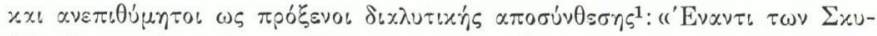

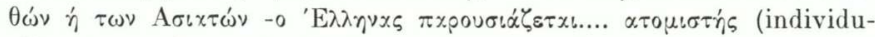

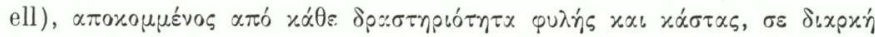

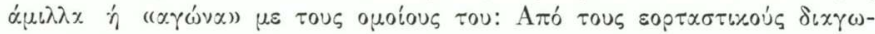

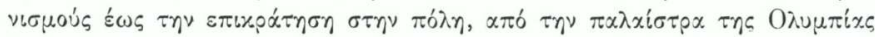

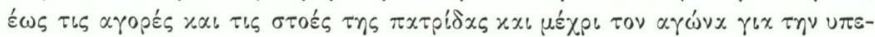

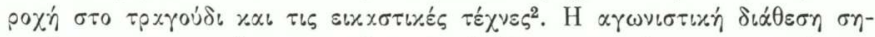

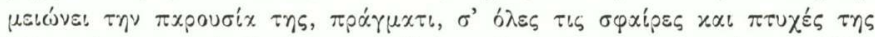

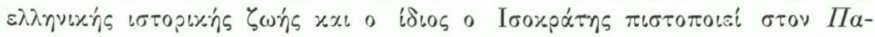

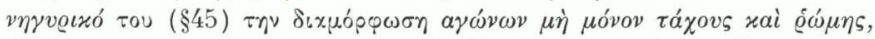

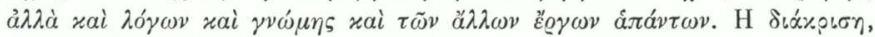

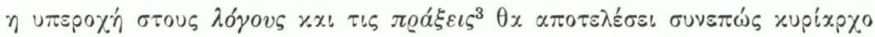

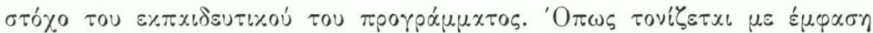

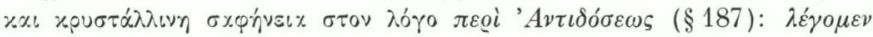

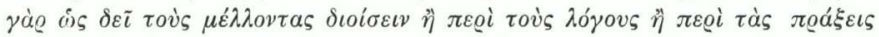

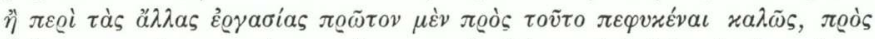

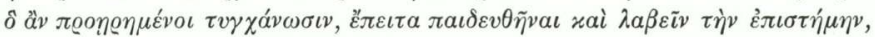

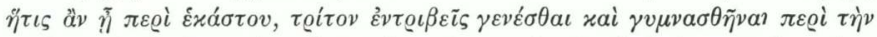

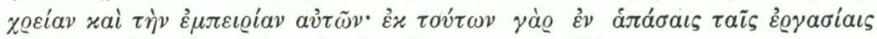

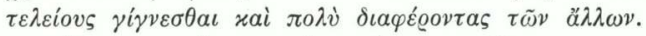

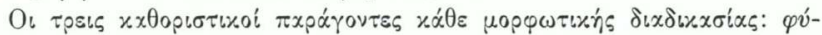

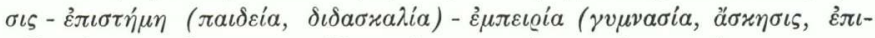

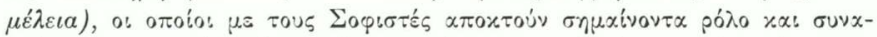

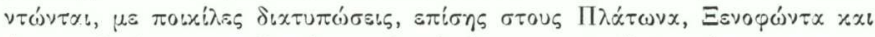

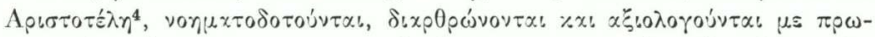

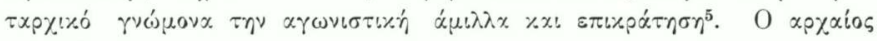

1. J. Burckhardt, Griechische Kulturgeschichte I, München 1977(11898-1902), 292 ห.ع.

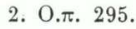

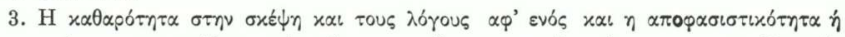

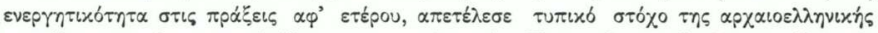

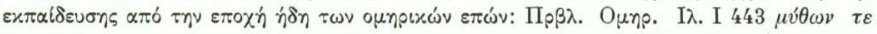

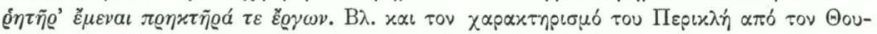

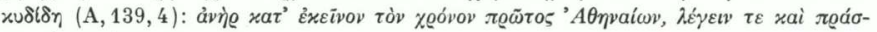

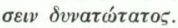

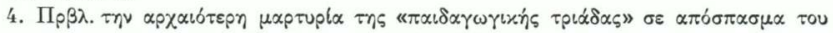

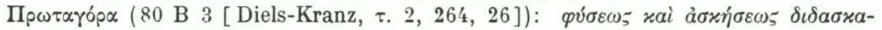

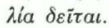

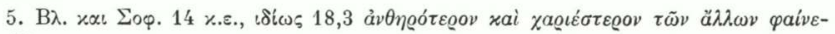

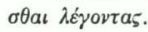




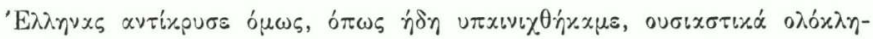

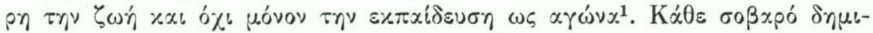

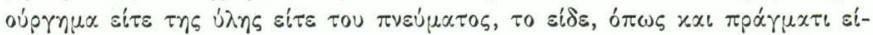

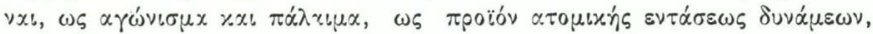

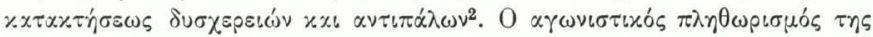

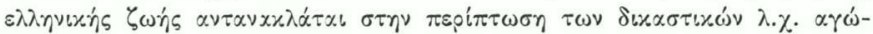

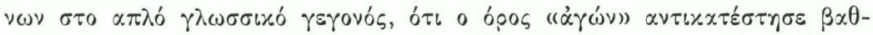

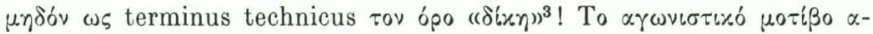

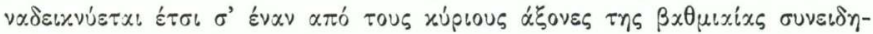

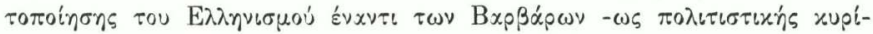

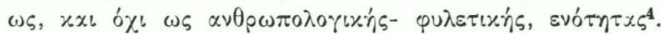

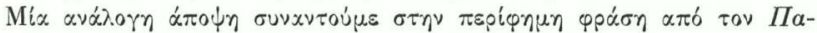

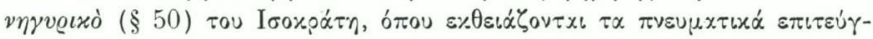

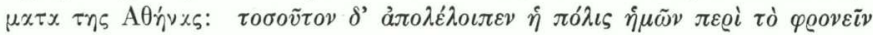

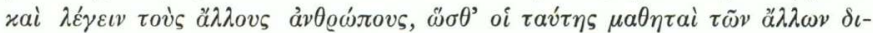

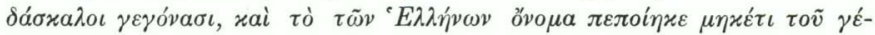

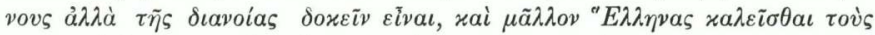

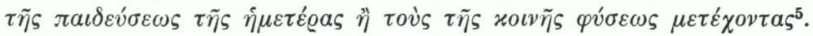

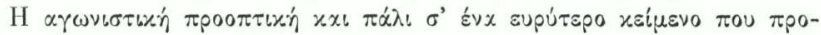

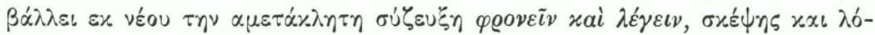

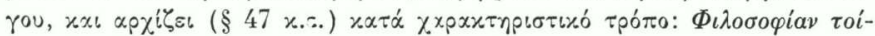

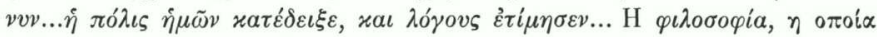

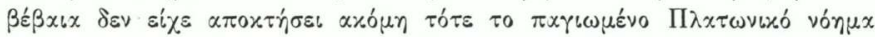

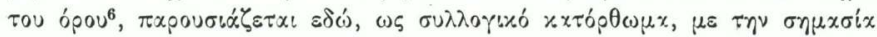

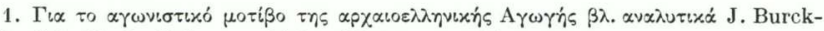

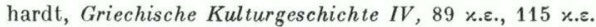

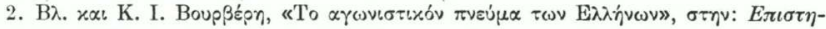

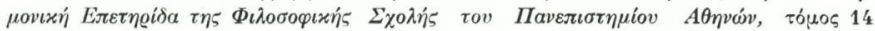
(1963-64), 306-320.

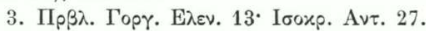

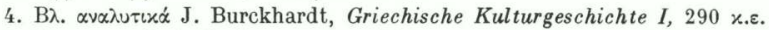

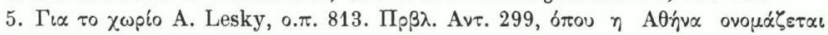
aั $\sigma \tau v \tau \tilde{\eta} \varsigma{ }^{`} E \lambda \lambda \dot{\lambda} \delta \circ \varsigma$.

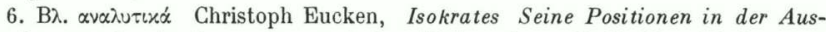
einandersetzung mit den zeitgenössischen Philosophen, Berlin-New York 1983,

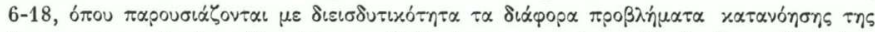

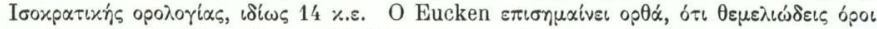

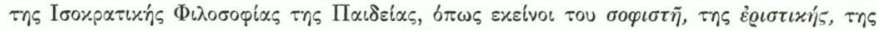

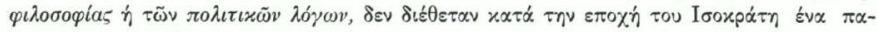

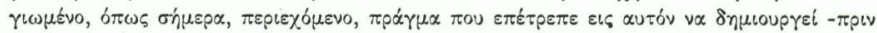

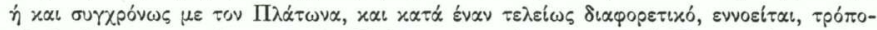

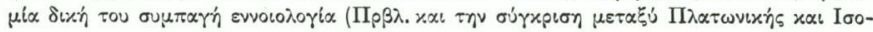




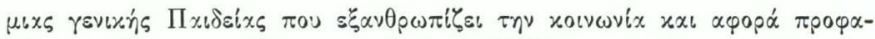

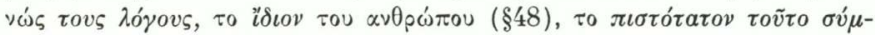

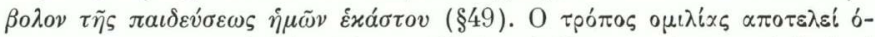

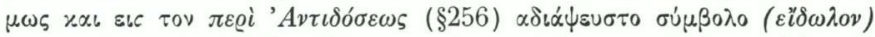

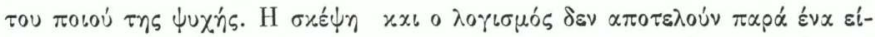

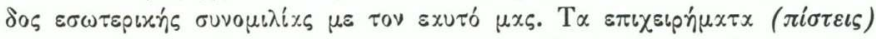

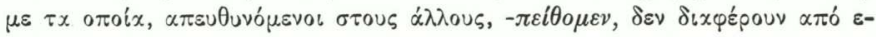

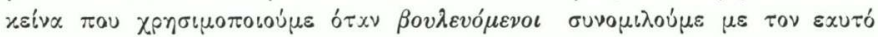

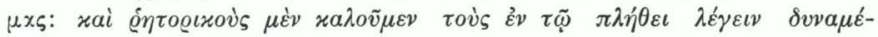

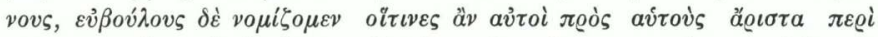

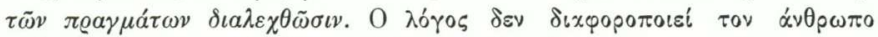

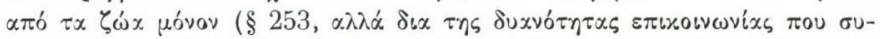

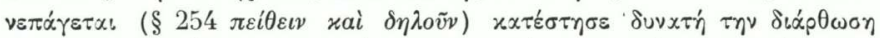

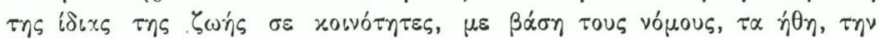

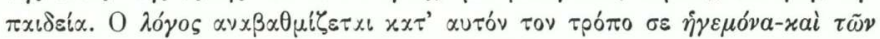

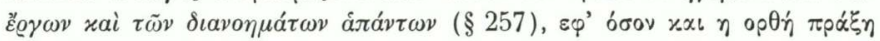

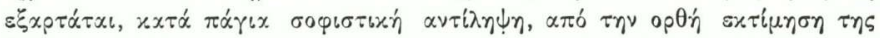

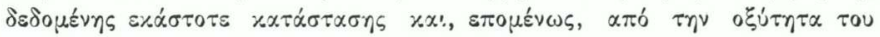
$\lambda o ́ \gamma o v$.

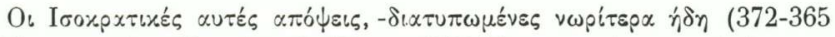

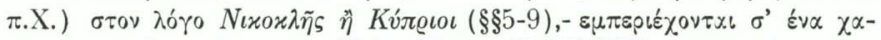

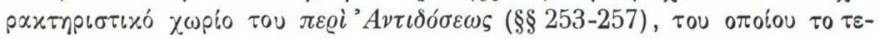

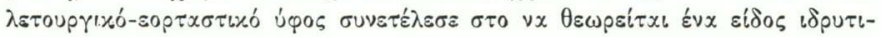

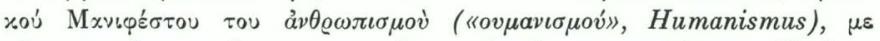

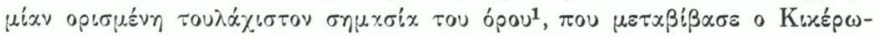

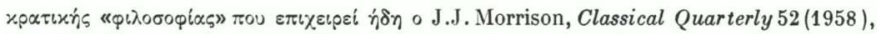

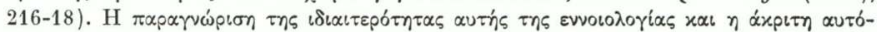

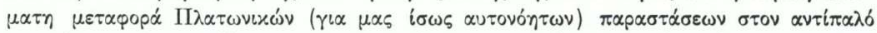

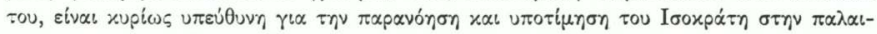

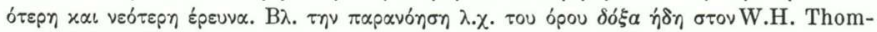
pson (ed.), The Phaedrus of Plato, With English notes and dissertations, London 1868, 177 (App. II-On the Philosophy of Isocrates, and his relation to the socratic schools: 170-183).

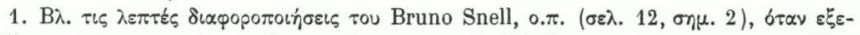

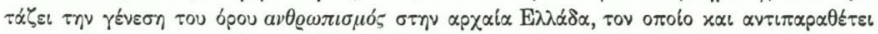

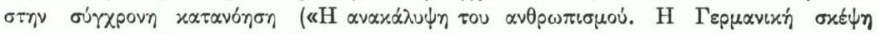

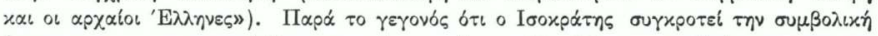

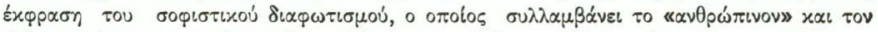
$\alpha v \theta p \omega \pi 0$ ó $\chi \iota$ б

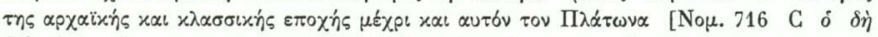

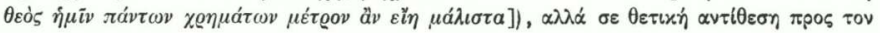




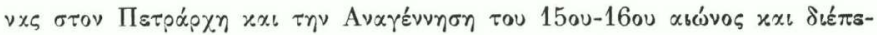

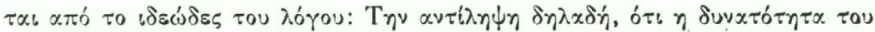

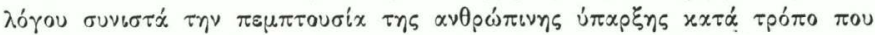

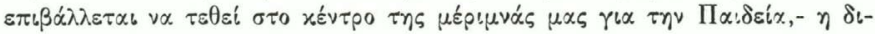

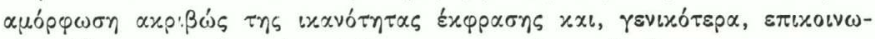

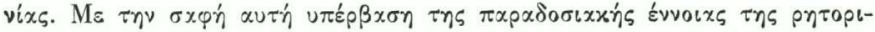

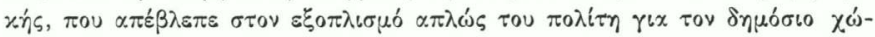

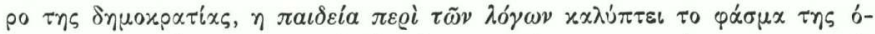

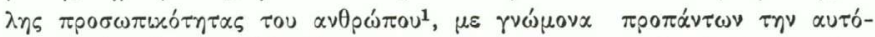

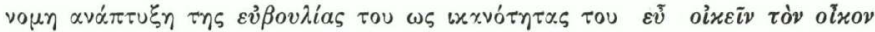

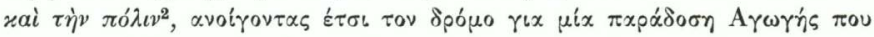

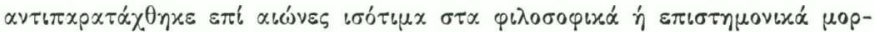

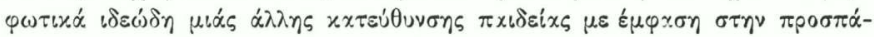

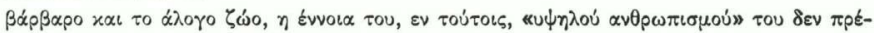

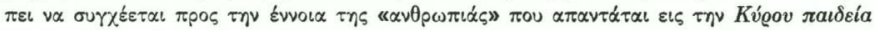

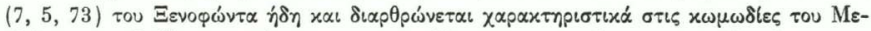

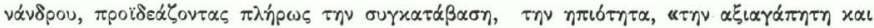

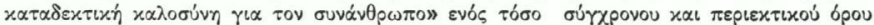

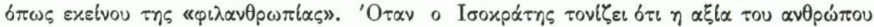

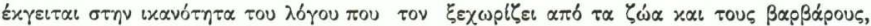

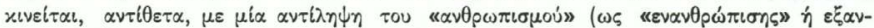

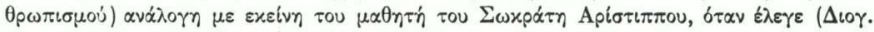

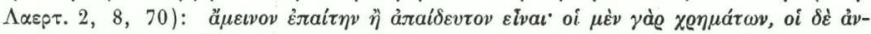

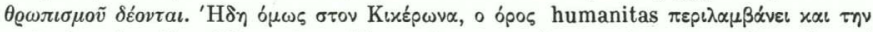

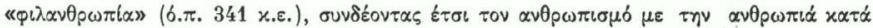

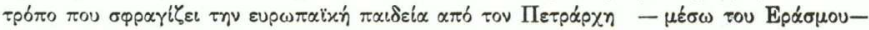

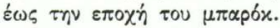

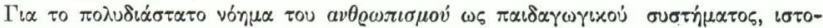

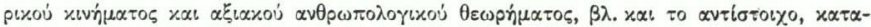

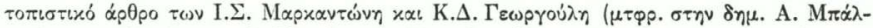

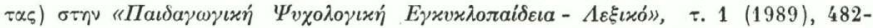

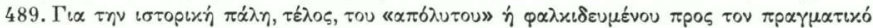

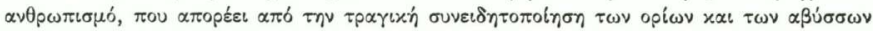

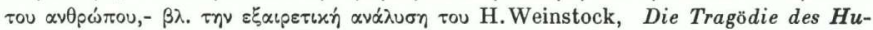
manismus. Wahrheit und Trung im abendländischen Menschenbild, Heidelberg 1953.

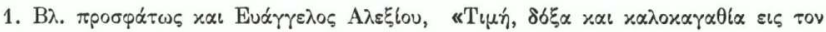

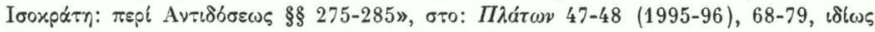
74.

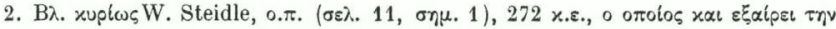

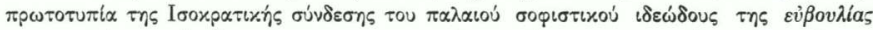

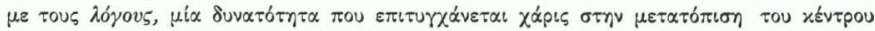

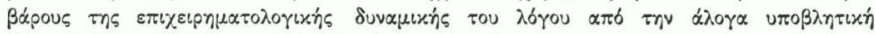

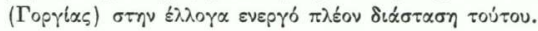




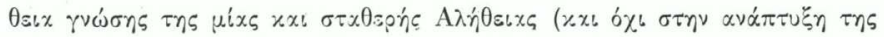

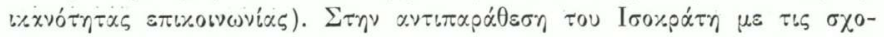

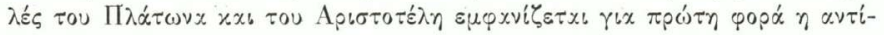

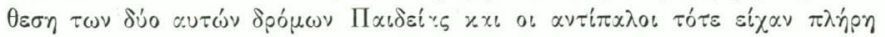

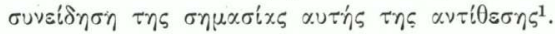

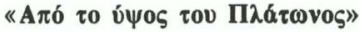

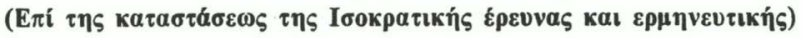

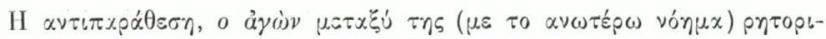

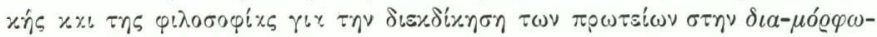

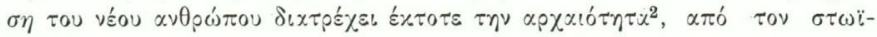

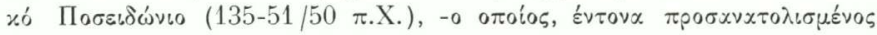

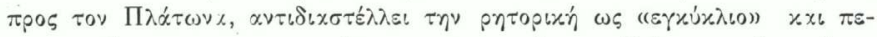

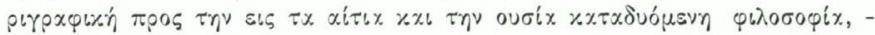

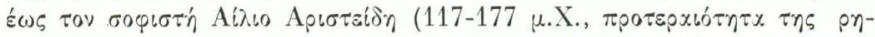

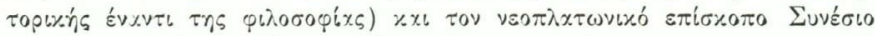

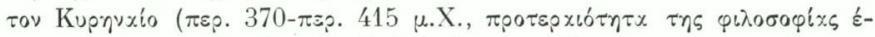

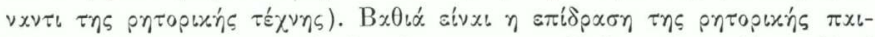

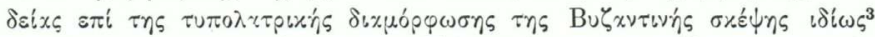

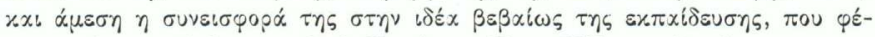

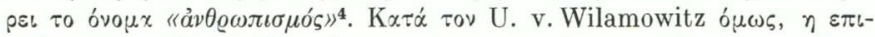

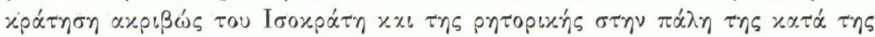

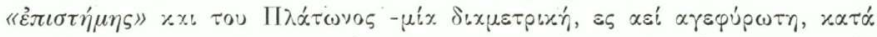

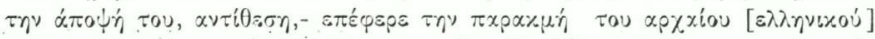

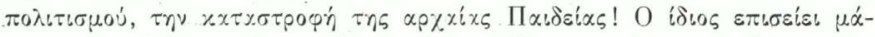

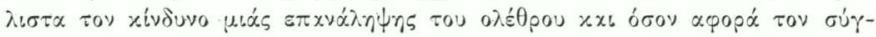

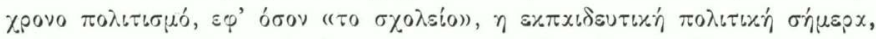

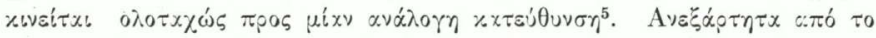

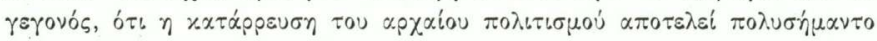

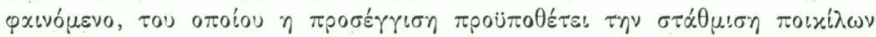

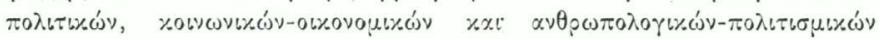

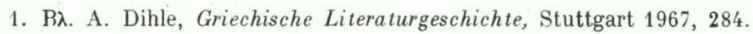

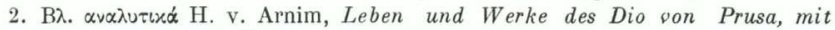
einer Einleitung: Sophistik, Rhetorik, Philosophie in ihrem Kampf um die Jugendbildung, Berlin 1898.

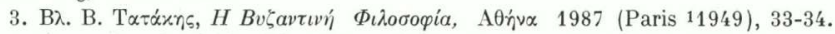

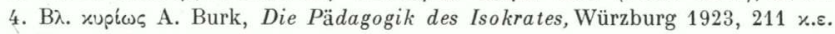

5. U. v. Wilamowitz, Platon II, 125. 


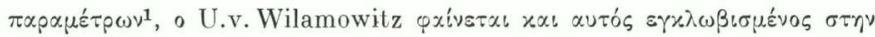

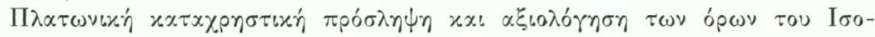

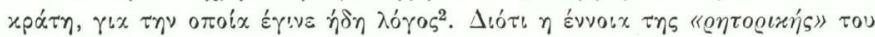

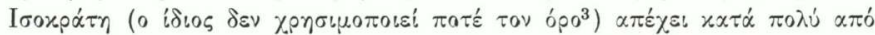

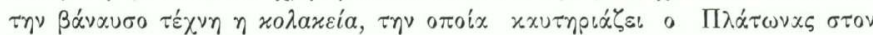

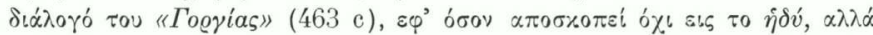

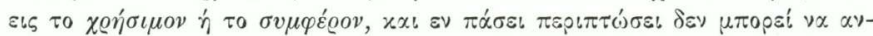

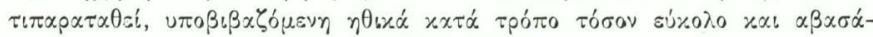

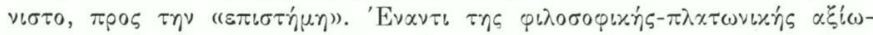

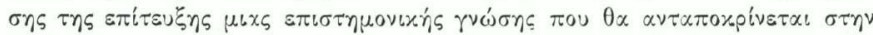

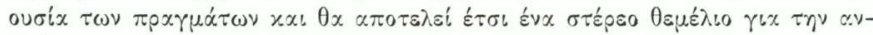

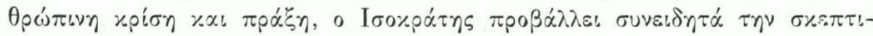

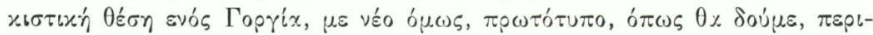

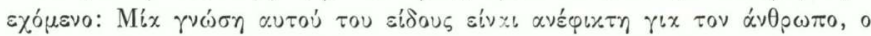

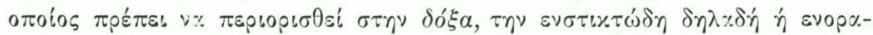

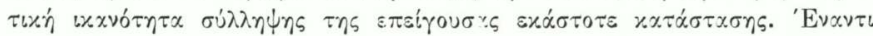

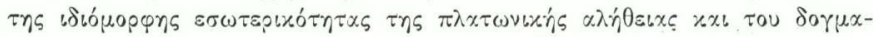

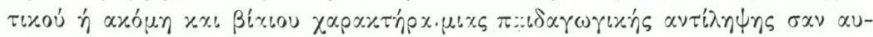

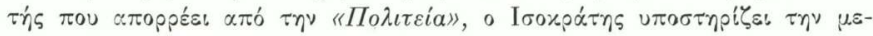

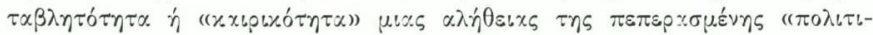

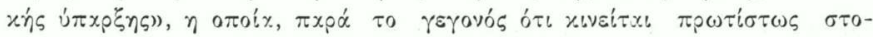

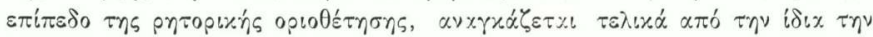

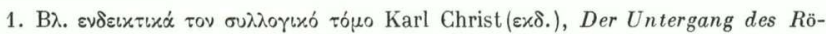

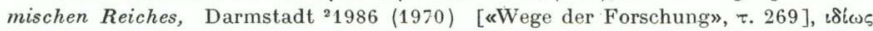

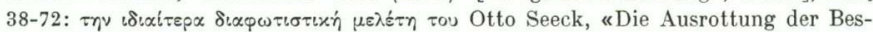
ten» (1895).

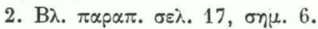

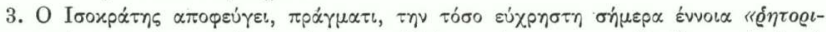

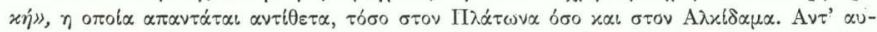

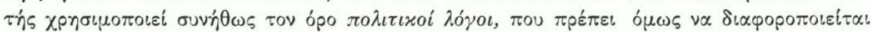

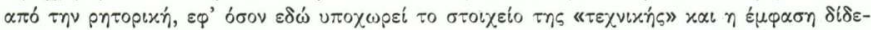

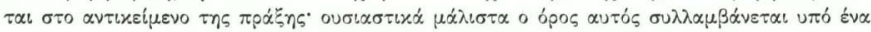

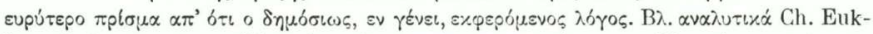

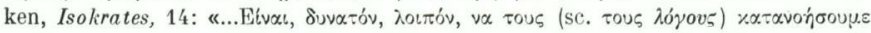

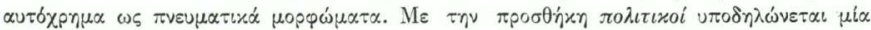

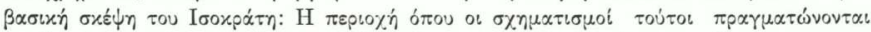

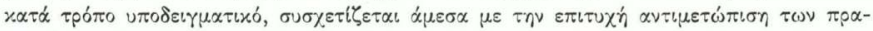

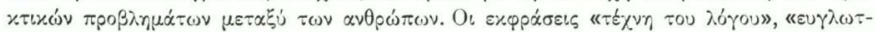

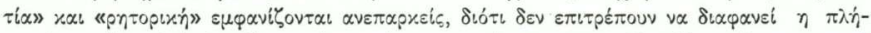

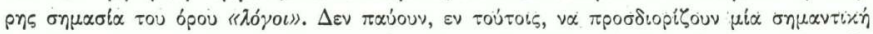

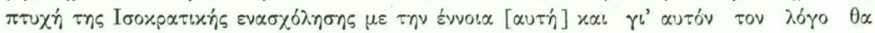

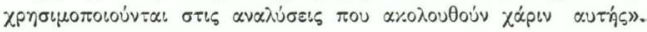




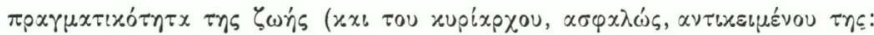

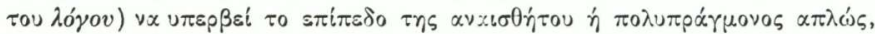

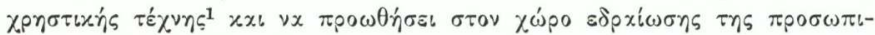

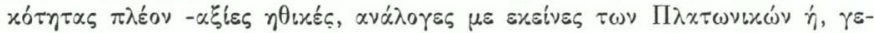

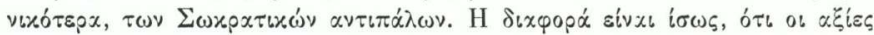

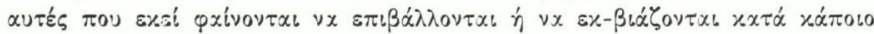

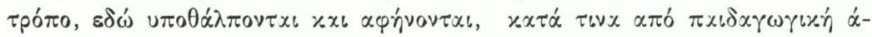

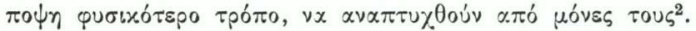

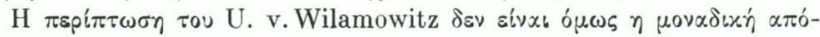

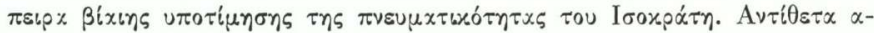

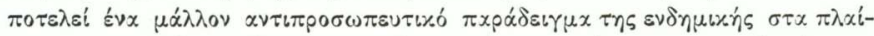

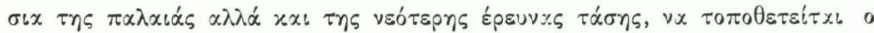

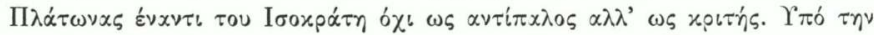

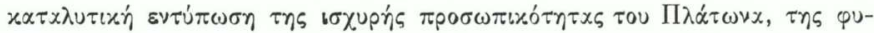

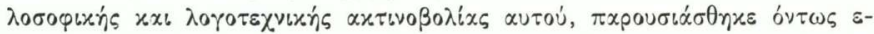

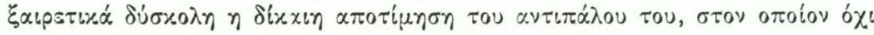

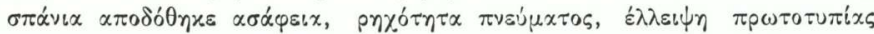

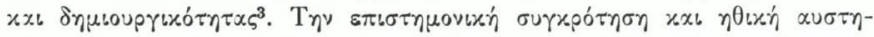

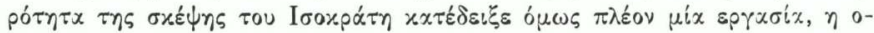

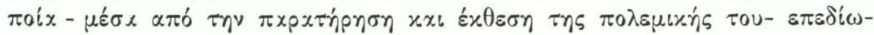

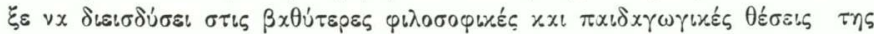

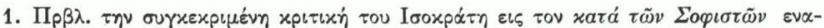

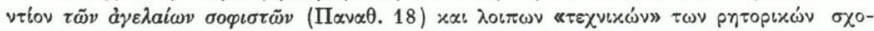

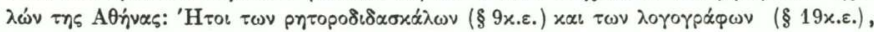

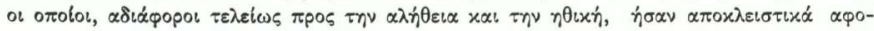

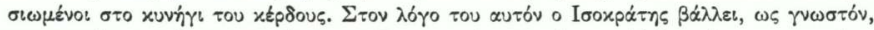

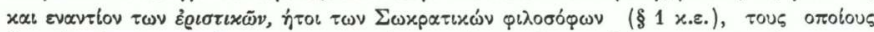

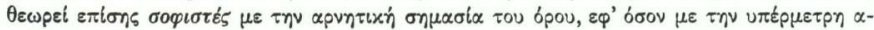

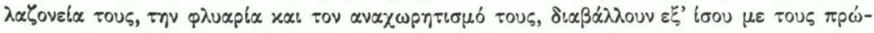

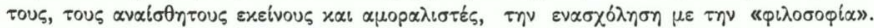

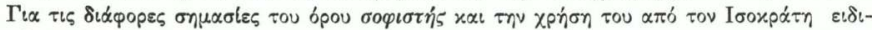

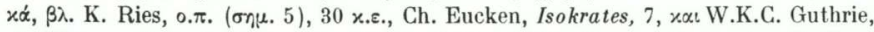

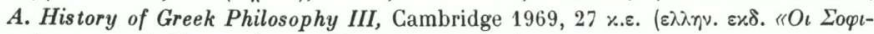

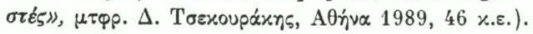

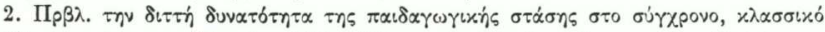

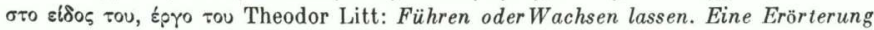
des pädagogischen Grundproblems, Stuttgart 1952.

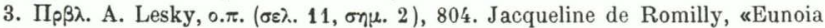
bei Isokrates oder die politische Bedeutung der Gewinnung von Wohlwollen»

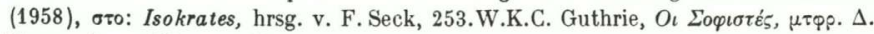
Toexouptxxy5, 454, onp. 42. 


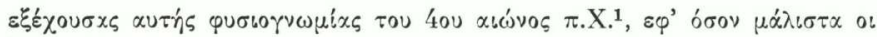

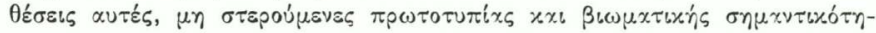

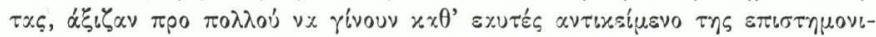

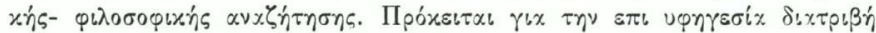

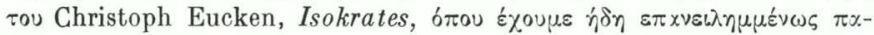

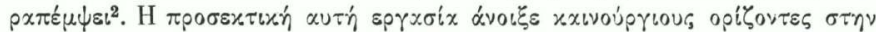

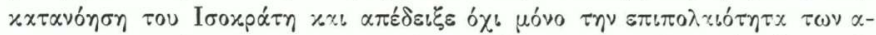

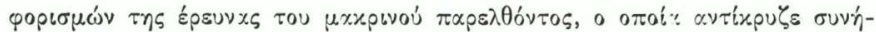

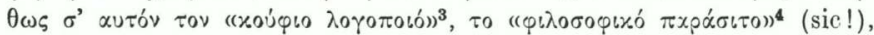

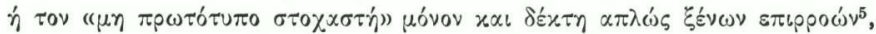

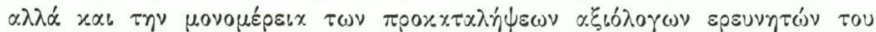

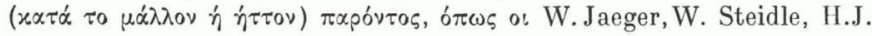

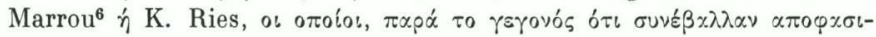

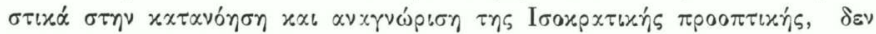

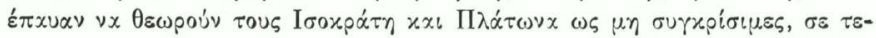
$\lambda \varepsilon u \tau \alpha i \alpha \propto \nu \alpha \dot{\lambda} \nu \sigma \eta, \pi \rho \circ \sigma \omega \pi\llcorner\alpha \dot{\tau} \tau \tau \varepsilon \zeta$.

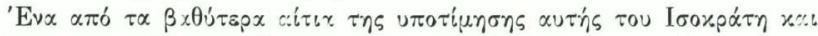

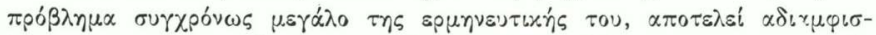

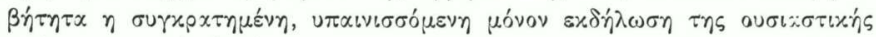

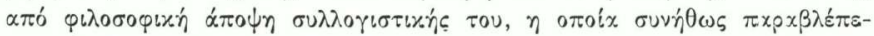

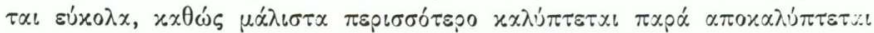

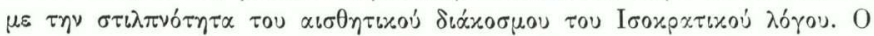

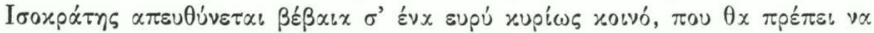

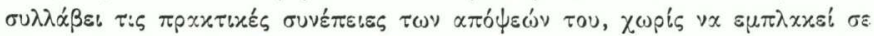

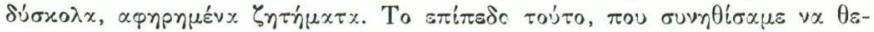

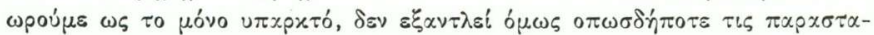
$\tau$

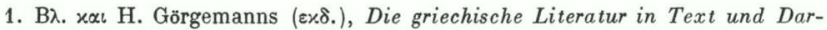
stellung, $\tau .3$ (Klassische Periode II), Stuttgart 1987, 106 x.є.

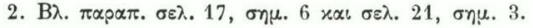

3. H. Gomperz, «Isokrates und die Sokratik II», $\sigma \tau 0$ : Wiener Studien 28 (1906), 35.

4. H. Raeder, «Alkidamas und Platon als Gegner des Isokrates», бто: Rheinisches Museum 63 (1908), 506.

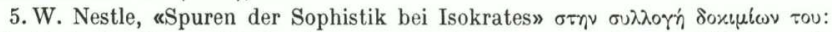

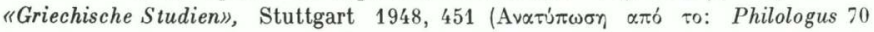

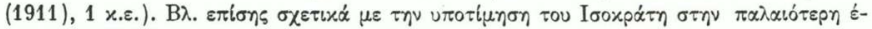

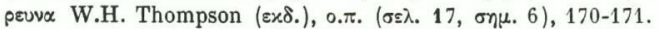

6. H.J. Marrou, Histoire de l'education dans l'antiquité, Paris ${ }^{81955 ~(1948), ~}$

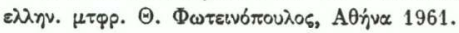




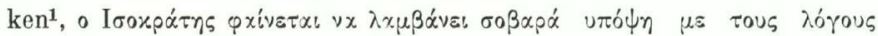

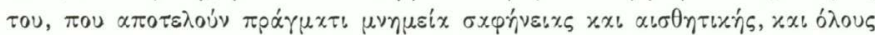

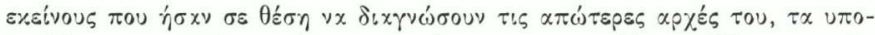

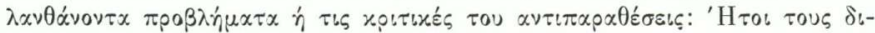

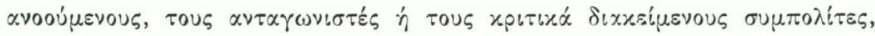

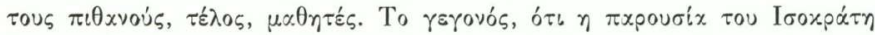

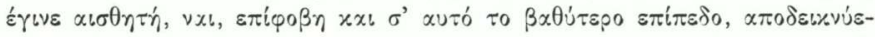

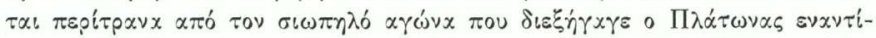

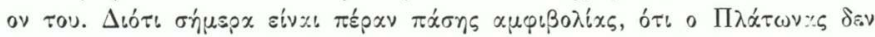

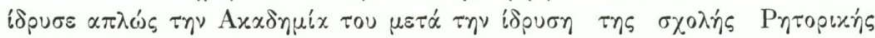

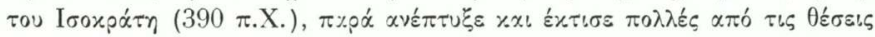

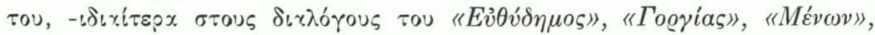

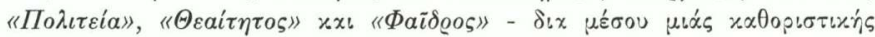

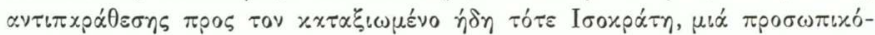

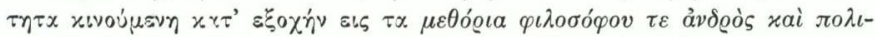

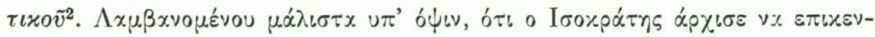

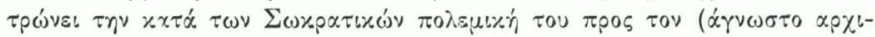

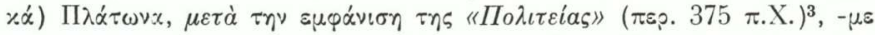

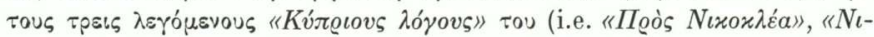

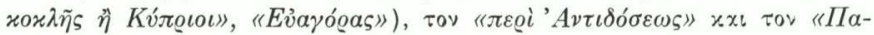

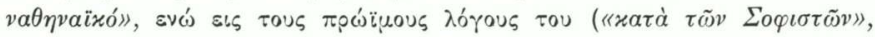

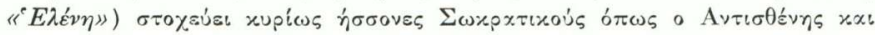

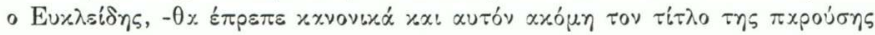

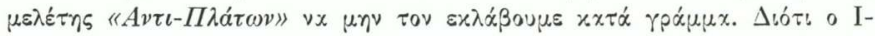

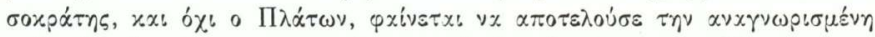

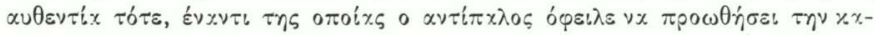

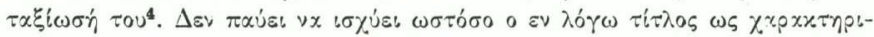

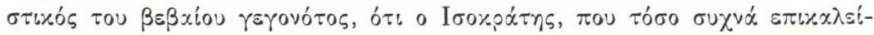

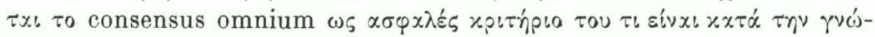

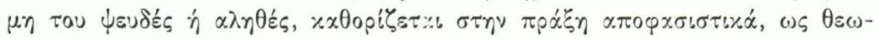

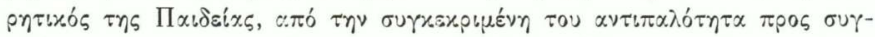

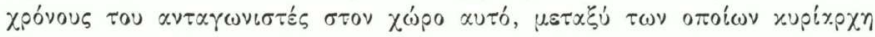

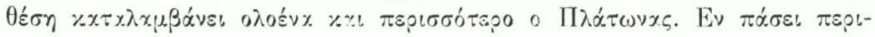

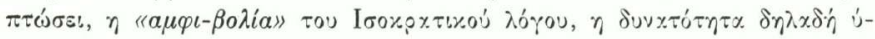

1. Ch. Euscken, Isokrates, 3-4.

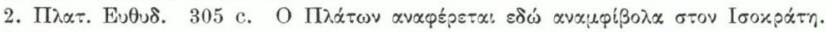

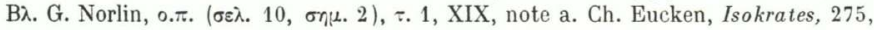
блp. 29.

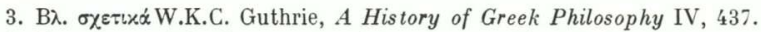

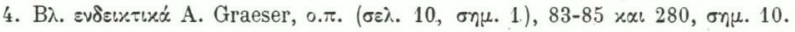




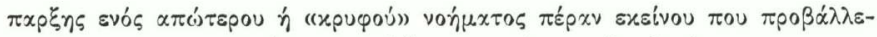

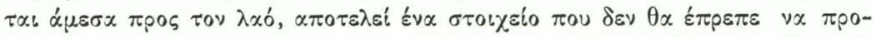

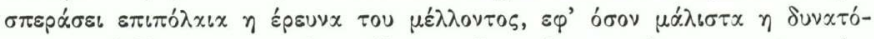

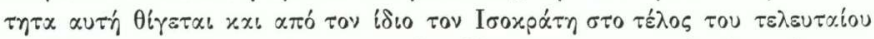

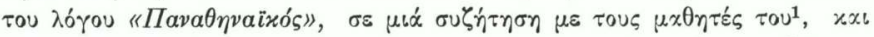

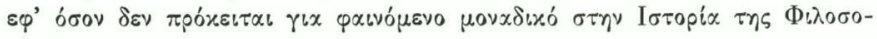
$\varphi \hat{\varphi} \alpha \varsigma^{2}$.

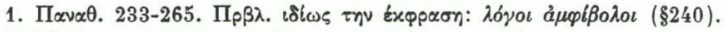

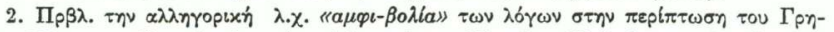
Yopiou Núøons: Charalambos Apostolopoulos, Phaedo Christianus. Studien zur $V e r b i n d u n g$ und Abwägung des Verhältnisses zwischen dem platonischen "Phaidon» und dem Dialog Gregors oon Nyssa "Über die Seele und die Auferstehung»,

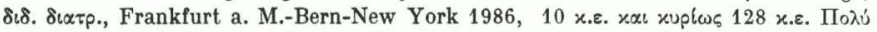

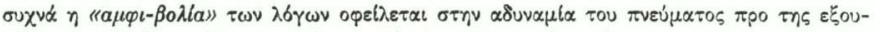

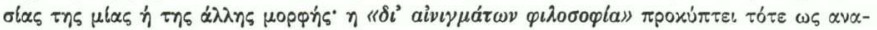

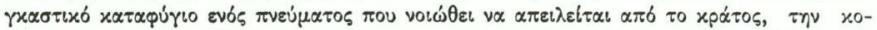

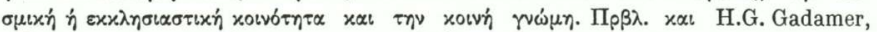

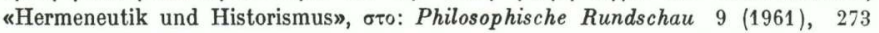

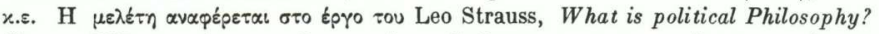

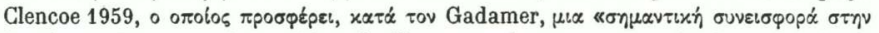

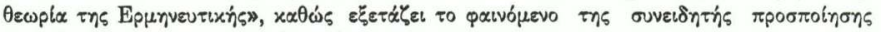

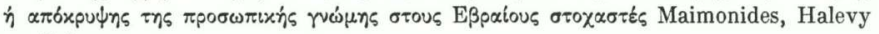
xar Spinoza. 